\title{
MODERNIDADE E MODERNISMO
}

\section{Maria Lúcia Bastos Kern*}

Para o estudo do modernismo no Brasil, torna-se importante delimitar os conceitos de modernidade e modernismo, bem como analisar a relação existente entre estes, nos países onde se originaram, e as formas peculiares que assumiram na nossa sociedade. Para que este estudo seja melhor efetivado, levar-se-à também em consideração a relação entre os países hegemônicos e subordinados, destacando-se em especial, nesta última classificação, o caso brasileiro. $^{1}$

Historicamente, a modernidade surge nos países europeus de longa tradição cultural, que já incorporaram o sistema capitalista, como um processo gradativo que acompanha as mudanças sociais. Inicialmente, esta se apresenta com os iluministas, como uma ideologia liberal, que se caracteriza pela defesa do individualismo e do racionalismo. O projeto dos filósofos iluministas consiste em organizar racionalmente a sociedade.

Mais tarde, com a Revolução Francesa, que possibilita a constituição do estado moderno, com o progresso científico, tecnológico e com a revolução industrial, a modernidade torna-se um modo de vida social. Atinge desta maneira amplos setores da sociedade, sendo que na arte chega mesmo a provocar rupturas em alguns setores.

Segundo Jürgen Habermas, a estética da modernidade caracteriza-se por atitudes centradas numa consciência diferente do tempo, a qual é revelada pela vanguarda. ${ }^{2}$ Esta rebela-se contra a tradição canônica, voltando-se em direção ao novo e tendo como fim ultrapassar o seu tempo e conquistar o futuro.

Nesta etapa da transformação da ordem social, o conceito de modernidade está relacionado à mudança que gera o progresso, em oposição ao passado e à tradição. 
Posteriormente, novas mudanças sociais se processam, como o crescimento demográfico, a concentração urbana, a divisão do trabalho e o aperfeiçoamento dos meios de comunicação de massa, o que tem como efeito a transformação do próprio conceito de modernidade. Esta passa a se articular sobre a mudança, a inovação, a instabilidade, a tensão, a crise e como representação ideal ou metodológica ${ }^{3}$, fugindo, assim, à meta dos iluministas.

A modernidade torna-se um valor e um mito, que esconde as suas contradições. Apesar de ser dinâmica e de condenar o aspecto normativo da tradição, a modernidade baseia-se em valores fixos, na mudança e na renovação - que desestruturam os hábitos e costumes tradicionais, mas sem romper com a tradição.

A modernidade perde, assim, o seu sentido revolucionário. A inovação passa a ser produzida voltada não só ao futuro, mas também ao passado.

A arte caracteriza-se pelo uso de formas do passado, as quais são destituídas do seu significado original, e são aliados à inovação.

A modernidade torna-se, deste modo, um jogo entre a tradição e o novo.

Segundo Baudrillard, perde o sentido de ruptura e se alimenta de vestígios de todas as culturas do passado, não só a nível formal, mas também técnico, como signo do antigo. ${ }^{4}$

Apesar da arte estar com laços presos à tradição, a modernidade na sociedade capitalista exige que esta também se baseie em valores fixos, como a renovação e a originalidade. $\mathrm{O}$ artista moderno tem como objetivo a renovação constante do sistema de representação visual, para obter, deste modo, a aceitação social e conseqüentemente o sucesso profissional.

A arte modernista é produzida, assim, sob o mito da originalidade, constituindo ao seu redor uma verdadeira estrutura, formada por críticos, pelo mercado de arte e pelos meios de comunicação que difundem e alardeiam a necessidade de consumir o novo. Isto ocorre até o momento em que o novo é superado por outra forma de expressão original, que coloca o mecanismo novamente em funcionamento, defendendo agora outras necessidades. 
O modernismo simboliza, deste modo, o culto do novo pelo novo, de modo irrefletido e acrítico. É a a exaltação do moderno, que busca se impor sem discussão. Ao passo que a modernidade se apresenta despojada do ufanismo modernista, caracterizandose por projetar uma certa reflexão sobre a inovação, que serve como uma espécie de controle da mesma.

$\mathrm{Na}$ sociedade capitalista, os meios de comunicação de massa promovem o moderno, fazendo com que as pessoas, que não o aceitam, sintam-se rejeitadas e desatualizadas.

No século XIX, Baudelaire já identificava o moderno com a moda. Os dois fenômenos chegam mesmo a confundir-se, sendo difícil de discernir suas diferenças. Nos dois encontra-se tanto o durável, como o efêmero, mas o durável no novo torna-se "tradicional". O modernismo é, portanto, o culto da atualidade mutável. $^{5}$

Enquanto a modernidade nos países hegemônicos se processa em amplos setores da sociedade, sendo, assim, gerada por mudanças sociais, ideológicas e por revoluções de ordem política e de ordem econômica; no Brasil ela se introduz, em alguns setores apenas, como uma espécie de reflexo das transformações na prática de vida destes países.

"Os procedimentos técnicos, os artigos manufaturados, os serviços e os hábitos de vida e de consumo gerados pela revolução industrial, transformam a sociedade brasileira, começando a urbanizá-la em moldes 'modernos' antes de a industrializar diretamente." 6

Um dos problemas da modernização no Brasil é justamente desta se processar em alguns setores, de maior interesse dos países industrializados, ao lado de outros que têm sua estrutura arcaica mantida, antes de produzir a mudança básica, que é a industrialização autônoma e a constituição de um mercado interno.

A modernidade surge imediatamente como uma prática de vida social, que se dá de modo parcial dentro da sociedade, provocando, assim, contradições maiores do que as que ocorrem nos seus países de origem. 
Para Florestan Fernandes, a modernização nos países latino-americanos não só é parcial e incompleta, mas também de "segunda grandeza". Isto se deve ao fato de o desenvolvimento provocado não ser auto-sustentado. ${ }^{7}$

A urbanização no Brasil se inicia no século XIX e é provocada, em parte, pela introdução de novos recursos técnicos para o desenvolvimento dos engenhos no nordeste e para a exploração do café em São Paulo, graças, de certo modo, aos investimentos ingleses. Outros também contribuem para acelerar o processo de urbanização, como a abolição da escravatura, que possibilita o aumento do mercado consumidor; e as iniciativas empresariais e públicas que reforçam a necessidade de modernização das cidades.

Esta relação de fatos históricos que agem e provocam a modernidade parcial vem ao encontro da tese de Fernando Henrique Cardoso de que as "estruturas dependentes não podem ser concebidas como meramente reflexas" como sugere Darcy Ribeiro. Ao contrário, estas estruturas "têm uma dinâmica própria dentro dos limites definidos pelas relações de dominação-subordinação entre países". 8

São as condições internas - política e social - que, associadas à dinâmica dos países hegemônicos, têm possibilidades de provocar o crescimento econômico e a modernização dos países subordinados. Entretanto, esta relação de dominação-subordinação não isenta o estabelecimento de um certo controle dos processos de crescimento e de modernização, nesta última categoria.

As mudanças podem ser concebidas como meramente reflexas, quando se configura uma situação de dominação colonial, na qual estas são geradas por transformações na metrópole. Nas sociedades modernas, a situação de subordinação é mais complexa, visto que a integração ao mercado internacional se dá em função da criação de um sistema de importações-exportações, no qual apesar da dependência exige um "certo grau de dinamismo e modernização". 9 


\section{MODERNISMO NO BRASIL}

O processo de industrialização no Brasil é produzido devido não só ao rompimento do sistema importação-exportação durante a 1ạ guerra, mas também resulta dos capitais originários da agricultura, os quais são mobilizados para este fim.

A modernidade surge, inicialmente, em São Paulo, como prática de vida social, graças ao fato da industrilização ter sido mais intensa neste estado.

Neste momento, a elite dirigente tem consciência da situação de subordinação do país, devido ao atraso econômico e cultural, bem como pela sua estrutura de herança colonial.

A consciência desta situação, em substituição ao ufanismo do início do século, serve como estímulo à industrialização, à busca de atualização cultural e à expansão de um nacionalismo de oposição aos países hegemônicos.

O modernismo desenvolve-se, primeiramente, em São Paulo, por constituir-se num centro industrial e urbano, com características cosmopolitas. Estas condições praticamente inexistem no resto do país.

Neste estado, a burguesia encontra-se em fase de ascensão, o proletariado cresce em termos numéricos e participa de movimentos reivindicatórios, assim como um setor médio oriundo da pequena empresa, do comércio e da burocracia começa também a atuar de modo significativo.

Todos estes segmentos demonstram o seu descontentamento com a estrutura mantida pelas oligarquias rurais e lutam para sua mudança, surgindo, com isto, organizações de caráter ideológico variado. Em 1921, por exemplo, a direita cria a revista ORDEM, que é encabeçada por Jackson de Figueiredo; no ano seguinte, é fundado o Partido Comynista, que tem como meta a articulação do proletariado, dá-se a Revolta do Forte de Copacabana, liderada pelos tenentes, os quais estão insatisfeitos com o modelo político e econômico vigente. O ano de 1922 é o marco também do centenário da Independência e a realização da Semana de Arte Moderna, em São Paulo. 
Esta manifestação modernista é financiada por uma fração da oligarquia rural e pela burguesia industrial, sendo os seus organizadores e autores também originários destes segmentos.

Apesar da semana ser uma espécie de símbolo do movimento modernista, não se pode deixar de salientar que a exposição de 1917, realizada por Anita Malfatti, foi responsável pela articulação de intelectuais e artistas. É a partir deste momento, que o movimento propriamente dito se constitui, com o objetivo inicial de destruir a arte acadêmica e todos aqueles conceitos trazidos pela missão artística francesa de 1816, que ainda vigoram.

Após a semana de 22, os teóricos e artistas modernistas mudam um pouco os seus objetivos, passando a se preocupar mais com a construção de uma arte e uma cultura nacionais. Visam com isto não só buscar uma identidade própria, mas também superar o atraso cultural e a situação de dependência em relação à Europa.

Entretanto, os modernistas, quando buscam a atualização artística, dirigem-se à Europa e em especial à França. E acabam assimilando as formas produzidas pelas vanguardas históricas expressionismo, fovismo, cubismo, surrealismo - que foram revolucionárias nos seus países de origem pelas suas propostas e por provocarem um rompimento com a arte institucionalizada, isto é, com a ideologia imagética dominante.

Estas formas criadas pelas vanguardas são copiadas de modo superficial, deixando de lado, quase sempre, suas propostas revolucionárias ou adotando-as numa estrutura social totalmente diferente e estranha à sua de origem.

As pinturas de Léger e de André Lothe, por exemplo, que representam uma fase pós-cubista, mais conservadora, posterior ao cubismo revolucionário de Picasso e Braque, foram seguidas por Tarsila do Amaral, na fase pau-brasil, mas dentro de uma proposta nacionalista.

Ao mesmo tempo que os modernistas assimilam as proposições formais das vanguardas históricas, eles também fazem uso de elementos do "Retour à I'ordre", que na França significa uma espécia de volta à tradição. ${ }^{10}$ 
A pintura de Tarsila da fase pau-brasil e as pinturas de Di Cavalcanti, posteriores à sua viagem à Paris, baseiam-se na "construção" objetiva, que é própria a este movimento. Di Cavalcanti parece ter sofrido influência da obra de Picasso da fase tradicional, pelo uso de figuras monumentais e pela manutenção da separação figura/fundo, como, por exemplo, nas telas "Modelo no atelier" e "Samba" de 1925. ${ }^{11}$

Existe, portanto, uma contradição entre o discurso ideológico dos artistas e a práxis. Negam o tradicional, mas fazem uso deste, sem ter talvez a consciência disto.

$\mathrm{Na}$ fase pau-brasil, Tarsila exalta signos da modernidade, como chaminés de fábrica, estradas de ferro, arranha-céus, etc., com o objetivo de demonstrar que São Paulo é tecnologicamente desenvolvida como outro centro cosmopolita Europeu. Alia aos signos da modernidade a natureza e a cor tropical, com o fim de tornar a sua pintura nacional. Esta reunião de signos aparece nas telas "E.F.C.B.", "São Paulo" de 1924, "Gare" e "O mamoeiro" de 1925.

A modernidade é cantada pelos modernistas como um meio de salientar as mudanças ocorridas em São Paulo e o seu cosmopolitismo, segundo eles, comparável a Paris, afirmando, assim, a necessidade de uma arte mais atualizada e moderna.

Como a arte de vanguarda pesquisa as culturas denominadas "primitivas", que os artistas europeus conhecem através dos museus, alguns dos nossos artistas, ao retornarem da Europa, buscam dar uma identidade própria à arte, fazendo uso de técnicas e de elementos formais da arte indígena. Os modernistas descobrem que existe o "primitivo" na sua sociedade e que poderiam utilizá-lo. É o caso de Vicente do Rêgo Monteiro que estuda a arte marajoara e executa uma pintura quase escultórica, na qual as figuras são modeladas em formas geométricas rígidas, apresentando sempre uma postura frontalista como a arte "primitiva". Como, por exemplo, "Pietá" de 1924 e "Adoração dos Reis Magos" do ano seguinte.

Já outros modernistas apropriam-se da cultura popular como sinônimo de primitiva - que foi durante o período da arte acadêmica depreciada pelas suas interpretações ingênuas e, portanto, distantes do pensamento erudito. 
Os modernistas representam, nesta busca do popular, a sua preocupação em dar à arte importada uma marca nacional. Demonstram com isto uma concepção quase romântica em relação à cultura popular, na medida em que vêem nesta a autenticidade nacional e a pureza cultural, sem influência da cultura erudita.

A apropriação do popular simboliza para os modernistas não apenas uma modalidade para tornar a arte brasileira, mas também um meio para romper, definitivamente, os laços com o academismo.

Deve-se salientar que o uso de certos traços da cultura popular faz com que estas percam os seus significados originais, visto que são retirados do seu círculo e levados a outro, o da cultura erudita.

Ainda com a finalidade de caracterizar a arte como uma representação simbólica nacional, alguns artistas pesquisam o barroco, considerando-o como uma expressão artística brasileira.

Esta questão é bastante discutível, pois sabe-se que a arte barroca foi imposta pelo colonizador português. Quando esta não era trazida de Portugal, ela era copiada de gravuras de livros europeus, visto que os artistas locais eram mais executores do que criadores. Eles não tinham passado por uma formação sistematizada como os europeus e não possuíam também a cultura erudita destes.

O fato de aparecerem, na arte barroca, traços étnicos do mulato, elementos da flora e da fauna tropical e uma interpretação quase ingênua da temática religiosa, não torna esta arte nacional, visto que a forma continua sendo européia. Apenas a faz peculiar.

Tarsila usa muito nas suas pinturas da fase pau-brasil os rosas e os azuis celestes da arte barroca, bem como a ingenuidade popular e as cores caipiras. Estes elementos são utilizados como signo do nacional, assim como a paisagem tropical, apesar da forma, continuar sendo européia. Por exemplo, as telas "Os anjos" de 1924 e "A família brasileira" de 1925.

A situação de subordinação cultural faz com que os artistas modernistas busquem soluções para a questão do nacional, misturando propostas e formas das vanguardas européias com elementos simbólicos brasileiros. 
Os artistas e os teóricos do movimento modernista supervalorizam certos traços culturais, que são por eles considerados nacionais, como uma forma de libertação e de negação da cultura dos países hegemônicos. Entretanto, não são estes elementos simbólicos que fazem a arte nacional.

Além disto, ocorre também o fenômeno da "queima de etapas", devido à defasagem e à simultaneidade com que a arte principalmente francesa - é absorvida. Este fenômeno aparece claramente no modernismo, chegando a caracterizar as contradições internas do movimento. ${ }^{12}$ Ao mesmo tempo que assimila os "ismos" revolucionários, adota também o "retorno à ordem" que representa a volta à tradição, tão negada e criticada pelos teóricos do modernismo.

Este movimento, nas artes plásticas nos anos 20, dá-se apenas em São Paulo, difundindo-se na década seguinte ao Rio de Janeiro, e a partir dos anos 40, aos outros estados brasileiros. Nestes assume formas específicas, devido, em parte, à grande defasagem entre a arte européia e a de São Paulo.

As contradições do movimento modernista, bem como da modernidade no país, representam as suas relações econômicas de subordinação. A própria defasagem do movimento paulista em relação à Europa e a lentidão da sua difusão no resto do país refletem esta situação de desequilíbrios produtivos provocados, em parte, pela situação de subordinação econômica e cultural.

\section{NOTAS}

* Este artigo faz parte de um projeto de pesquisa - "O modernismo nas artes plásticas do RGS" - desenvolvido com auxílio financeiro da FUNARTE.

1 Será usado o termo país subordinado, porque os termos subdesenvolvido, dependente, periférico estāo comprometidos com teorias, as quais em algumas questões precisam ser revisadas.

CHASIN, José. O integralismo de Plínio Salgado - forma de regressividade no capitalismo hiper-tardio. São Paulo, Ciências Humanas, 1978, pp.37-38.

2 HABERMAS, Jürgen. "Modernidade versus pós-modernidade". In: Arte em Revista. São Paulo, Centro de estudos de arte contemporânea, (7) agosto 1983, p.86.

3 BAUDRILLARD, Jean. "Modernité". In: Encyclopaedia Universalis 2, Paris, 1968, p. 140.

4 Op. cit., p. 140.

5 LEFEBVRE, Henri. Introduction à la modernité. Paris, Minuit, 1962, p.184.

6 RIBEIRO, Darcy. As Américas e a civilização. Petrópolis, Vozes, 1983, p. 269. 
7 FERNANDES, Florestan. Capitalismo dependente e classes sociais na América Latina. Rio de Janeiro, Zahar, 1975, p. 80.

8 CARDOSO, Fernando Henrique. Mudanças sociais na América Latina, São Paulo, Difel, 1969, p. 17.

9 CARDOSO, F.H. e FALETTO, Enzo. Dependência e desenvolvimento na América Latina. Rio de Janeiro, Zahar, 1970, p. 32.

10 O "Retour à l'ordre" desenvolve-se no após 1 a Guerra na França, com o objetivo de difundir uma arte construtiva, contrária a todos os ismos das vanguardas, que simbolizavam a "destruição".

11 Consultar ZILIO, Carlos. A querela do Brasil. Rio de Janeiro, FUNARTE, 1982.

12 KERN, Maria Lúcia B. "Arte e ideologia: o modernismo nos anos 20". In: Estudos Ibero-Americanos, PUC/RS, IX (1983) 1/2.

Pontifícia Universidade Católica do Rio Grande do Sul Departamento de História 